\title{
Functional evaluation using motor scores after cervical spinal cord injuries
}

\author{
Eiren Toh, Toru Arima, Joji Mochida' ${ }^{1}$, Masanari Omata and Shizuka Matsui \\ Department of Orthopaedic Surgery, Hakone National Hospital, 412 Kazamatsuri, Odawara, Kanagawa 250; \\ ${ }^{1}$ Department of Orthopaedic Surgery, Tokai University School of Medicine, Bohseidai, Isehara, Kanagawa 259-11, \\ Japan
}

\begin{abstract}
Patient evaluation using Zancolli's classification for cervical cord injuries uses easily understood criteria and accurately defines the state of disability in Frankel grade A or B patients. However, this classification cannot be used in Frankel grade C patients even though they also cannot walk. We compared the Zancolli classification with American Spinal Injury Association (ASIA) motor scores in evaluating self-care in Frankel grade $\mathrm{C}$ patients. The Zancolli classification was found to correlate closely with the ASIA motor score. The threshold of ability to perform self-care in areas such as urinary toileting and wheelchair mobility occurred approximately between $\mathrm{C} 6 \mathrm{~A}$ and $\mathrm{C} 6 \mathrm{~B} 1$ in the Zancolli classification in Frankel grade $\mathrm{A}$ and $\mathrm{B}$ patients and at the level of about 30 points in the ASIA motor score in Frankel grade $\mathrm{C}$ patients. The ASIA motor score is helpful in defining functional motor status in Frankel grade $\mathrm{C}$ patients with cervical spinal cord injuries.
\end{abstract}

Keywords: cervical spinal cord injury; activities of daily living (ADL); American Spinal Injury Association (ASIA) motor score; Zancolli's classification; Frankel grading scale

\section{Introduction}

The spinal level above which motor function is preserved has obvious importance in evaluating selfcare activities of daily living (ADL) in patients with cervical spinal cord injuries. In this respect, the state of disability is better described using the Zancolli classification of preserved upper extremity motor function than by Frankel grades such as A or B. For example, patients may transfer unaided to a wheelchair if motor function is preserved at the level of $\mathrm{C} 6 \mathrm{~B}$, and may manage intermittent catheterization if function is preserved at the level of C8. However in Frankel grade $\mathrm{C}$ patients, the Zancolli classification is inadequate to describe function, even though they also cannot walk. In the present study we compared the results of the Zancolli classification with those of the American Spinal Injury Association (ASIA) motor score in evaluation of self-care in Frankel grade $\mathrm{C}$ patients.

\section{Patients and methods}

Seventy patients admitted to our hospital for treatment of cervical spinal cord injuries between 1993 and 1995 were studied, including 28 in Frankel grade A, 16 in grade $\mathrm{B}$, and 26 in grade $\mathrm{C}$. Vertebral bone injuries were present in 36 patients, including burst fracture in seven, tear-drop dislocation fracture in 12 , anterior

Correspondence: E Toh, Department of Orthopaedic Surgery, Tokai University School of Medicine, Bohseidai, Isehara, Kanagawa 259 11, Japan dislocation or dislocation fracture in 16, and indeterminate bone injuries in one case. Thirty-four patients without bone injuries included 20 with cervical spondylosis, 11 with ossification of the cervical posterior longitudinal ligament and three with cervical intervertebral disc hernia or other injury.

Sixty-five patients were male while five were female. Age at injury ranged from 12 to 69 years (mean: 42.2). The duration of post-trauma follow-up ranged from 2 to 24 years, (mean: 4.5 ).

The cervical spinal level above the lesion responsible for paralysis was determined in Frankel grade A and B patients using the Zancolli classification of preserved motor function in the upper extremity, and the level on the side with better motor function was used when motor function differed between right and left upper extremities (Tables 1 and 2). ${ }^{1,2}$ As for Frankel grade $\mathrm{C}$ patients, ASIA motor scores for each upper extremity spinal level, were graded as 0 to 5 giving a maximum of 50 points, and compared with the results of the Zancolli classification for Frankel grade A and B patients (Table 3 ). ${ }^{3}$

Next, the level of paralysis and the degree of selfcare for basic ADL, including eating, urination, and transfer between bed and wheelchair (bed-W/C transfer), were examined as to the need for aid and method of performance, in order to determine the relationship between ASIA motor score and ADL.

In evaluation of ADL, patients were separated into three groups with respect to eating: needing personal 
assistant (helper), modified utensils for self-assistance (device), and no device. Device and no device were considered to be independent. Regarding urination, patients were divided into four groups: suprapubic cystostomy (cystostomy), reflex bladder-aid-self, and clean intermittent catheterization (CIC). Patients capable of self-managed reflex bladder or CIC were considered to be independent. The border between dependence and independence for bed-W/C transfer were judged by whether the patients could transfer without assistance.

One author (E Toh) carried out all examinations, assisted by a physical therapist.

Table 1 Frankel grading scale

A Complete: The lesion was complete both motor and sensory below the segmental level

B Sensory only: Some sensation was present below the level of the lesion, but motor paralysis was complete

C Motor useless: Some motor power was present below the lesion, but of no practical use

D Motor useful: Useful motor power below the level of the lesion

E Intact: Free of neurologic symptoms

Table 2 Zancolli classification

\begin{tabular}{|c|c|c|}
\hline \multirow[t]{2}{*}{$\mathrm{C} 5$} & A & Without brachioradialis \\
\hline & B & With brachioradialis \\
\hline \multirow[t]{5}{*}{ C6 } & A & Weak wrist extension \\
\hline & B & Strong wrist extension \\
\hline & & 1 Without pronator teres and flexor carpi radiaris \\
\hline & & $\begin{array}{l}2 \text { With pronator teres and without flexor carpi } \\
\text { radiaris }\end{array}$ \\
\hline & & $\begin{array}{l}3 \text { With pronator teres, flexor carpi radiaris and } \\
\text { triceps }\end{array}$ \\
\hline \multirow[t]{2}{*}{$\mathrm{C} 7$} & A & $\begin{array}{l}\text { Complete extension of ulnar fingers and paralysis } \\
\text { of radial fingers and thumb }\end{array}$ \\
\hline & $\mathrm{B}$ & $\begin{array}{l}\text { Complete extension of all fingers and weak thumb } \\
\text { extension }\end{array}$ \\
\hline \multirow[t]{4}{*}{$\mathrm{C} 8$} & A & $\begin{array}{l}\text { Complete flexion of ulnar fingers and paralysis of } \\
\text { flexion of radial fingers and thumb }\end{array}$ \\
\hline & & Complete thumb extension \\
\hline & B & $\begin{array}{l}\text { Complete flexion of all fingers and weak thumb } \\
\text { flexion. Weak thenar muscles }\end{array}$ \\
\hline & & $\begin{array}{l}\text { Paralysis of the intrinsic muscles of the fingers } \\
\text { without or with flexor superficialis }\end{array}$ \\
\hline
\end{tabular}

Table 3 Upper extremity motor scoring system of the American Spinal Injury Association

\begin{tabular}{lll}
\hline Level & $R \quad L$ & Muscle group \\
\hline C5 & $\square \square$ & Elbow flexors \\
C6 & $\square \square$ & Wrist extensors \\
C7 & $\square \square$ & Elbow extensors \\
C8 & $\square \square$ & Finger flexors \\
T1 & $\square \square$ & Finger abductors \\
& $25+25=50$ points \\
\hline
\end{tabular}

\section{Results}

The Zancolli classification was statistically determined to correlate closely to the ASIA motor score in Frankel grade A and B patients $(r=0.920$ by Spearman's coefficient of rank correlation, $P<0.01 \%$, Figure 1).

Regarding eating in Frankel grade A and B patients, the demarcation between dependence on aid and independence was located approximately between C5A and C5B by the Zancolli classification (Table 4a). Frankel grade $\mathrm{C}$ patients had a motor score of 16 points or more, and none of them required aid to eat (Table 4b).

As for urination, the division between dependence on aid and independence was located between C6A and $\mathrm{C} 6 \mathrm{~B} 1$ by the Zancolli classification in Frankel grade $\mathrm{A}$ and $\mathrm{B}$ patients (Table 5a), because many C6B 1 or better patients could manage CIC. In Frankel grade $\mathrm{C}$ patients, the threshold motor score differentiating between dependence and independence for urination was less distinct, but occurred in the range of 26-30 points (Table 5b).

The division between dependence and independence for bed-W/C transfer was located approximately between C6A and C6B 1 by the Zancolli classification for Frankel grade A and B patients (Table 6a). Because there were only two, C6A patients, the judgement was difficult. Bed-W/C transfer could not be achieved independently in most Frankel grade $\mathrm{C}$ patients having a motor score of 30 points or less (Table 6b).

The mean ASIA motor score was 23.7 points in Frankel grade A and B patients and 31.2 points in Frankel grade $\mathrm{C}$ patients, showing a statistically higher score in Frankel grade $\mathrm{C}$ patients by the Mann-Whitney $U$-test (Figure 2). The mean age at injury was 35.1 years in Frankel A and B patients and 51.3 years in Frankel $\mathrm{C}$ patients, clearly showing a larger number of older patients in Frankel grade $\mathrm{C}$ (Figure 3). As for fracture type, many Frankel grade $\mathrm{C}$

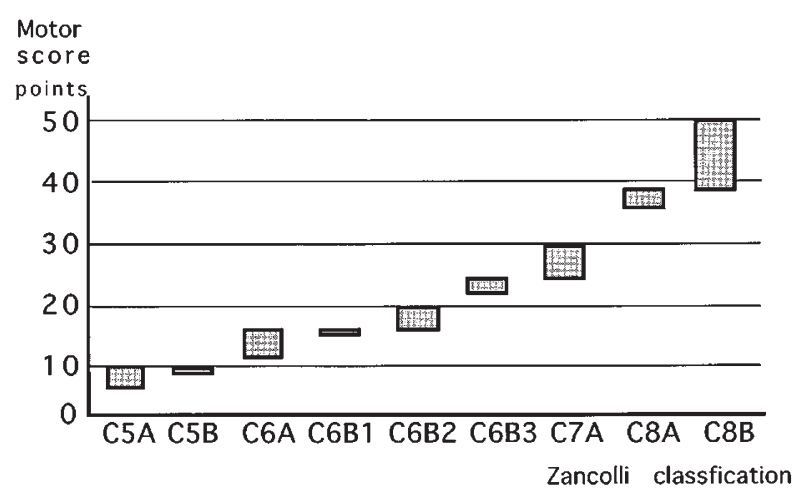

Figure 1 Correlation between Zancolli classification and ASIA motor score in Frankel grade $\mathrm{A}$ and $\mathrm{B}$ patients $(r=0.920$ by Spearman's coeffcient of rank correlation, $P<0.0001)$ 
Table 4 Self-care for eating in (a) Frankel grade A and B patients, and (b) grade $\mathrm{C}$

\begin{tabular}{|c|c|c|c|c|c|}
\hline $\begin{array}{l}\text { Zancolli } \\
\text { classifi- } \\
\text { cation }\end{array}$ & $\begin{array}{l}\text { Motor } \\
\text { Score }\end{array}$ & $\begin{array}{l}\text { Depen- } \\
\text { dence } \\
\text { helper }\end{array}$ & $\begin{array}{l}\text { Indep } \\
\text { Device }\end{array}$ & $\begin{array}{l}\text { endence } \\
\text { No device }\end{array}$ & No. \\
\hline $\mathrm{C} 4$ & (0) & 1 & & & 1 \\
\hline $\mathrm{C} 5 \mathrm{~A}$ & $(7-10)$ & 1 & 1 & & 2 \\
\hline C5B & $(9-10)$ & 1 & 3 & & 4 \\
\hline C6A & $(12-16)$ & & 2 & & 2 \\
\hline C6B 1 & $(16-17)$ & & 7 & & 7 \\
\hline C6B 2 & $(16-20)$ & & 7 & & 7 \\
\hline C6B 3 & $(22-24)$ & & 7 & & 7 \\
\hline C7A & $(24-30)$ & & 3 & & 3 \\
\hline C8A & $(36-38)$ & & 1 & 4 & 5 \\
\hline $\mathrm{C} 8 \mathrm{~B}$ & $(38-50)$ & & & 6 & 6 \\
\hline
\end{tabular}

Frankel $\mathrm{A}$ and $\mathrm{B}$, total 44

b

\begin{tabular}{lccc}
\hline $\begin{array}{l}\text { Motor } \\
\text { score }\end{array}$ & \multicolumn{3}{c}{ Independence } \\
Device & No device & No. \\
\hline $16-20$ & 4 & & 4 \\
$21-25$ & 3 & & 3 \\
$26-30$ & 7 & & 7 \\
$31-35$ & 2 & 2 & 4 \\
$36-40$ & 2 & 2 & 4 \\
$41-45$ & 1 & 2 & 2 \\
$46-50$ & & Frankel C, total 26 \\
& &
\end{tabular}

patients had no apparent fractures. About $60 \%$ of these patients showed an intramedullary signal abnormality at the $\mathrm{C} 3 / 4$ level on magnetic resonance imaging (MRI) (Figure 4).

\section{Discussion}

Various classifications have been employed by health care professionals to describe the status of patients with cervical spinal cord injuries. One representative system, the Frankel classification, provides a rough categorization which sometimes fails to accurately convey the state of motor function. We usually assume that Frankel grade $\mathrm{C}$ patients are unable to walk, even using self-assisting devices, such as a cane or braces, and Frankel grade D patients are able to walk using braces, for the reason that we can easily imagine the state of many patients with defined cervical spinal cord injuries.

However, because the Frankel classification system does not describe motor function in detail, particularly in patients with cervical spinal cord injuries, and because defining the most caudal cervical spinal level with preserved motor function is a logical method of expressing the extent of paralysis, we have used the Zancolli classification of preserved motor function in the upper extremity for severe cervical spinal cord injuries classified as Frankel A or B. In the Zancolli classification, each spinal level is divided into two or
Table 5 Self-care regarding urination in (a) Frankel grade A and $\mathrm{B}$ patients, and (b) grade $\mathrm{C}$

\begin{tabular}{lcccccc}
\hline $\begin{array}{l}\text { Zancolli } \\
\text { classifi- } \\
\text { cation }\end{array}$ & $\begin{array}{c}\text { Motor } \\
\text { score }\end{array}$ & $\begin{array}{c}\text { Dependence } \\
\text { Cysto- } \\
\text { stomy }\end{array}$ & $\begin{array}{c}\text { Reflex } \\
\text { Aid }\end{array}$ & $\begin{array}{c}\text { Independence } \\
\text { bladder } \\
\text { Self }\end{array}$ & CIC & No, \\
\hline C4 & $(0)$ & 1 & & & & 1 \\
C5A & $(7-10)$ & 1 & 1 & & & 2 \\
C5B & $(9-10)$ & 4 & & & & 4 \\
C6A & $(12-16)$ & 1 & 1 & & & 2 \\
C6B 1 & $(16-17)$ & 2 & 1 & & 4 & 7 \\
C6B 2 & $(16-20)$ & 2 & 2 & & 3 & 7 \\
C6B 3 & $(22-24)$ & 2 & 2 & & 3 & 7 \\
C7A & $(24-30)$ & 1 & & & 2 & 3 \\
C8A & $(36-38)$ & & & 1 & 4 & 5 \\
C8B & $(38-50)$ & & & 1 & 5 & 6
\end{tabular}

Frankel A and B, total 44

b

\begin{tabular}{lccccc}
\hline $\begin{array}{l}\text { Motor } \\
\text { score }\end{array}$ & $\begin{array}{c}\text { Dependence } \\
\text { Cysto- } \\
\text { stomy }\end{array}$ & $\begin{array}{c}\text { Reflex } \\
\text { Aid }\end{array}$ & $\begin{array}{c}\text { Independence } \\
\text { bladder } \\
\text { Self }\end{array}$ & CIC & No. \\
\hline $16-20$ & 3 & 1 & & & 4 \\
$21-25$ & 1 & 2 & & & 3 \\
$26-30$ & & 3 & 4 & & 7 \\
$31-35$ & & 3 & & 1 & 4 \\
$36-40$ & & & 1 & 3 & 4 \\
$41-45$ & & & 1 & 1 & 2 \\
$46-50$ & & & & 2 & 2
\end{tabular}

Frankel C, total 26

Cytostomy; Suprapubic cystostomy. CIC; Clean Intermittent Catheterization

more segments, and with particular consideration being given to the level of $\mathrm{C} 6$, which is divided into four subgroups. This is important for the evaluation of ADL, because many borders of self-care exist at this level C6. These transition points have improved as a result of recent advances in self-assist devices and rehabilitation. ${ }^{4-8}$ However, it is difficult to clearly predict the potential for self-care in Frankel grade C patients because the Zancolli classification is applicable only to Frankel grade A and B, though Frankel grade $\mathrm{C}$ patients also are unable to walk.

The ASIA established a standard neurologic classification in 1994. We found that the Zancolli classification closely correlated with this ASIA motor score in Frankel A and B patients, suggesting the feasibility of using the ASIA motor score to evaluate the potential for self-care in Frankel grade C patients. We compared the degree of self-care between Frankel grade $\mathrm{A}$ and $\mathrm{B}$ patients and Frankel grade $\mathrm{C}$ patients using only the upper extremity motor scores from the ASIA system.

In our data, the reason for higher motor scores in Frankel grade C patients compared with Frankel grade $\mathrm{A}$ and $\mathrm{B}$ patients was thought to be that the motor score contained some impractical points of less than MMT (manual muscle testing) 2. In addition, the 
Table 6 Self-care in bed-W/C transfer in (a) Frankel grade $\mathrm{A}$ and $\mathrm{B}$ patients, and (b) grade $\mathrm{C}$

a

\begin{tabular}{lccc}
\hline $\begin{array}{l}\text { Zancolli } \\
\text { classification }\end{array}$ & $\begin{array}{c}\text { Motor } \\
\text { score }\end{array}$ & $\%$ \\
\hline C4 & $(0)$ & $0 / 1$ & 0 \\
C5A & $(7-10)$ & $0 / 2$ & 0 \\
C5B & $(9-10)$ & $0 / 4$ & 0 \\
C6A & $(12-16)$ & $1 / 2$ & 50 \\
C6B 1 & $(16-17)$ & $6 / 7$ & 86 \\
C6B 2 & $(16-20)$ & $5 / 7$ & 71 \\
C6B 3 & $(22-24)$ & $3 / 7$ & 43 \\
C7A & $(24-30)$ & $2 / 3$ & 67 \\
C8A & $(36-38)$ & $5 / 5$ & 100 \\
C8B & $(38-50)$ & $6 / 6$ & 100 \\
\hline
\end{tabular}

Frankel A and B: $27 / 44$

\begin{tabular}{lcc}
\hline b & & \\
\hline & $\begin{array}{c}\text { Motor } \\
\text { score }\end{array}$ & $\%$ \\
\hline $16-20$ & $0 / 4$ & 0 \\
$21-25$ & $0 / 3$ & 0 \\
$26-30$ & $1 / 7$ & 14 \\
$31-35$ & $4 / 4$ & 100 \\
$36-40$ & $4 / 4$ & 100 \\
$41-45$ & $2 / 2$ & 100 \\
$46-50$ & $2 / 2$ & 100 \\
\hline
\end{tabular}

Frankel C: $13 / 26$

actual degree of self-care fell below the apparent motor ability in this group because it contained many older patients with other disabilities. We inferred from MRI findings that injuries caused by excessive extension at $\mathrm{C} 3 / 4$ or higher often occurred in Frankel grade $\mathrm{C}$ patients as a result of immobility from agedrelated changes in the middle to lower cervical spine, such as cervical spondylosis. ${ }^{9-11}$

In the present study we compared the degree of selfcare in such activities of daily living as eating, urination, and bed-W/C transfer between Frankel grade A and B patients and Frankel grade $\mathrm{C}$ patients, in order to determine whether we could accurately depict the state of self-care in Frankel grade $\mathrm{C}$ patients using motor scores. The degree of self-care for eating was high in all Frankel grade $\mathrm{A}, \mathrm{B}$, and $\mathrm{C}$ patients.

The border of self-care with respect to urination was located between C6A and C6B 1 in Frankel grade A and $\mathrm{B}$ patients and at the level of about 30 points in Frankel grade $\mathrm{C}$ patients. Although some Frankel grade $\mathrm{A}$ and $\mathrm{B}$ patients with $\mathrm{C} 6 \mathrm{~B} 1$ or better had a cystostomy or required aid for urinary toileting, such patients had undergone cystostomy at other hospitals, had limb contractures, or were aged.

The border of self-care for bed-W/C transfer fell approximately between $\mathrm{C} 6 \mathrm{~A}$ and $\mathrm{C} 6 \mathrm{~B} 1$ by the Zancolli classification in Frankel grade $\mathrm{A}$ and $\mathrm{B}$ patients. Most Frankel grade $\mathrm{C}$ patients could not transfer to a wheelchair when they had an ASIA motor score of 30 points or less. Some Frankel grade

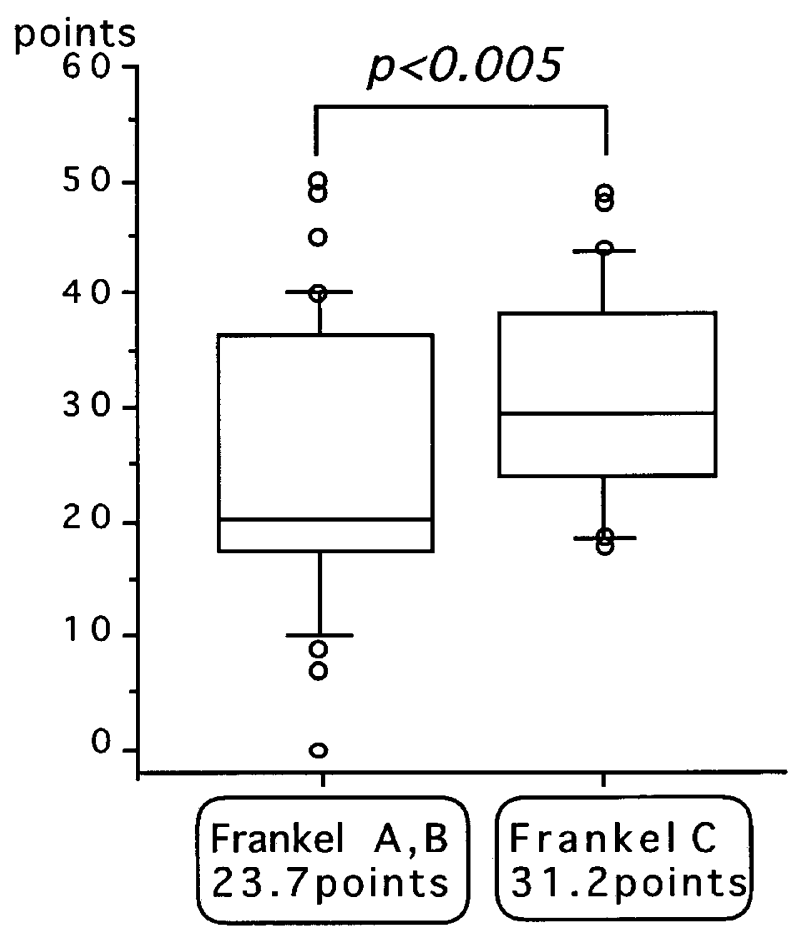

Figure 2 Box plots of ASIA motor score in Frankel grade A and $\mathrm{B}$ vs Frankel grade $\mathrm{C}$ patients

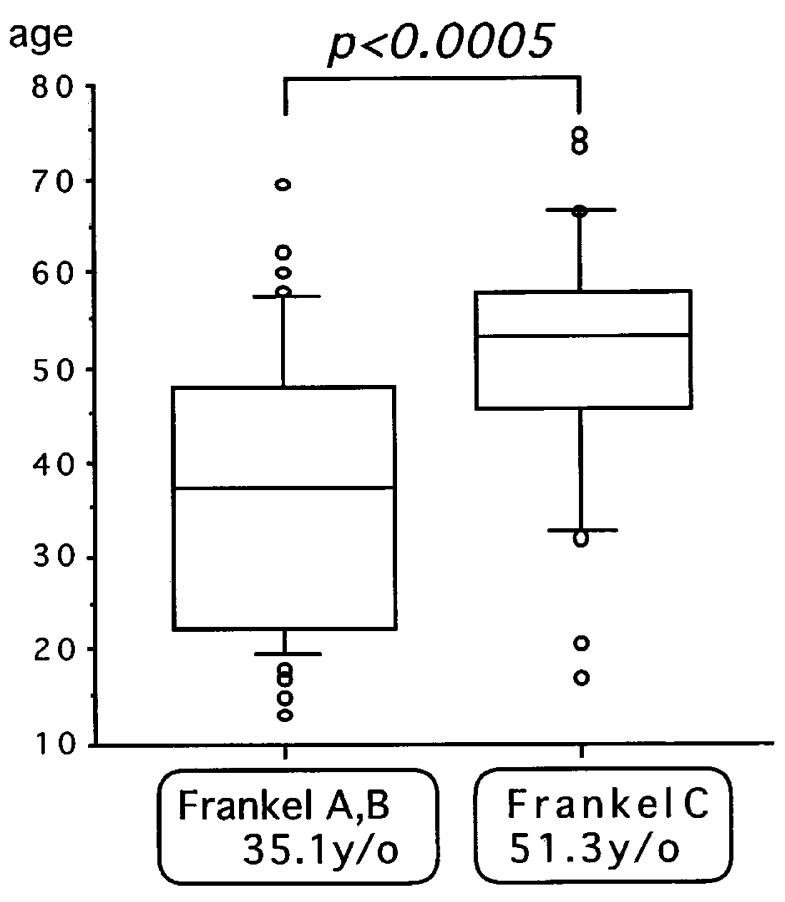

Figure 3 Box plots of age at injury in Frankel A and B patients $v s$ Frankel C patients

A and B patients with C6B2 on better had poor transfer ability because of either age or contractures. 


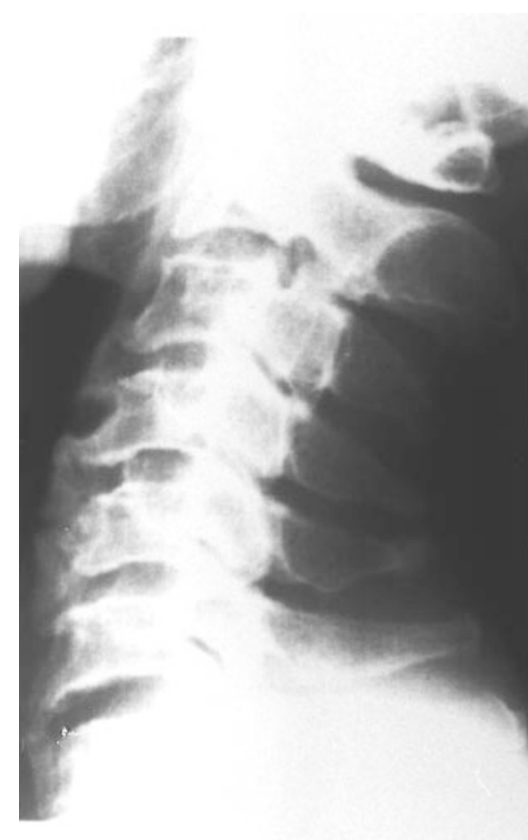

Radiograph

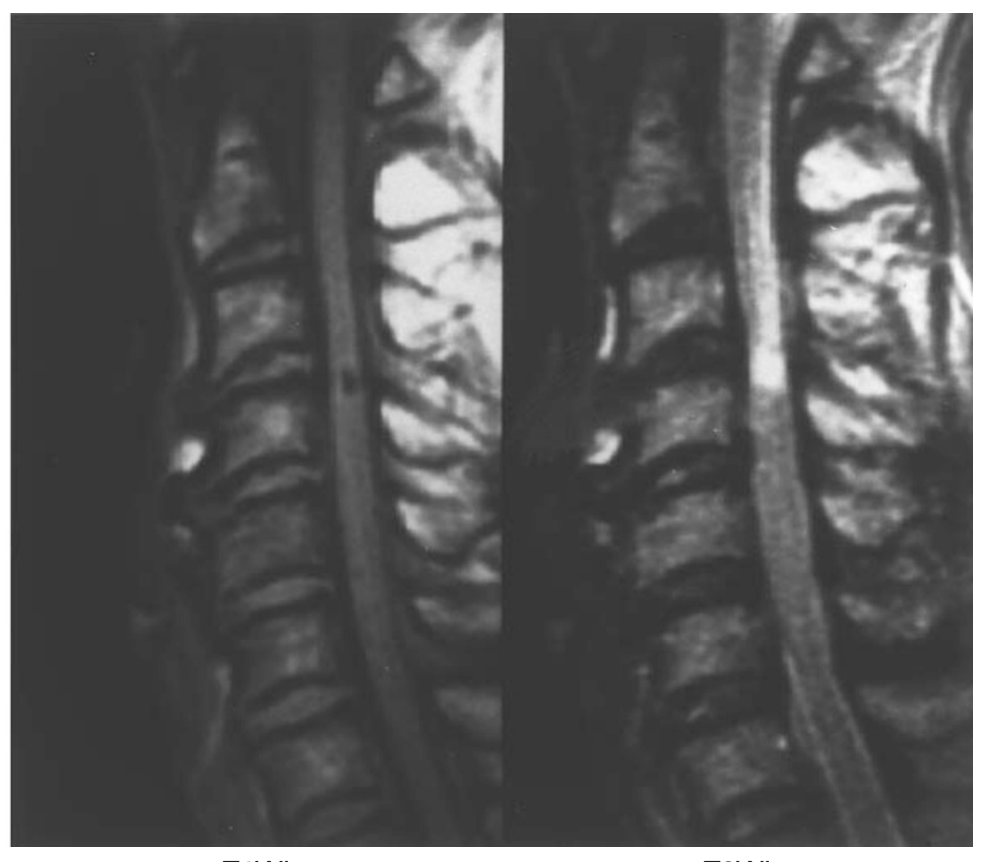

T1WI
$\mathrm{T} 2 \mathrm{WI}$

Figure 4 Many Frankel grade $\mathrm{C}$ patients had no fractures or dislocations, although about $60 \%$ showed an intramedullary signal abnormality at $\mathrm{C} 3 / 4$ on MRI.

We evaluated the degree of self-care for three basic activities of daily living, including eating, urination, and bed-W/C transfer, according to dependence or independence from aid. The overall border of self-care, assessed according to urination and bed-W/C transfer (eating was excluded because this activity could be achieved without aid by most patients) fell approximately between $\mathrm{C} 6 \mathrm{~A}$ and $\mathrm{C} 6 \mathrm{~B} 1$ by the Zancolli classification in Frankel grade A and B patients and at the level of about 30 points (ASIA motor score) in Frankel grade $\mathrm{C}$ patients.

Although it was more difficult to extrapolate degree of self-care from the ASIA motor scores of the upper extremities in Frankel grade $\mathrm{C}$ patients than from the Zancolli classification in Frankel grade $\mathrm{A}$ and $\mathrm{B}$ patients, we could predict self-care from the ASIA motor score in Frankel grade $\mathrm{C}$ patients to a significant extent, indicating its descriptive usefulness.

\section{Conclusions}

In patients with Frankel grade A or B injuries, the Zancolli classification was correlated closely with the ASIA motor score, suggesting that the ASIA motor score for the upper extremities could be useful in evaluation of potential for ADL in Frankel grade $\mathrm{C}$ patients, to whom the Zancolli classification does not readily apply.

Independence in activities of daily living correlated closely with the Zancolli classification as well as to the ASIA motor score of the upper extremities. The border of self-care for such basic activities of daily living as urinary toileting and bed-W/C transfer lies approximately between C6A and C6B 1 or at a level of about 30 points in the ASIA motor score in Frankel grade $\mathrm{C}$ patients.

\section{Acknowledgements}

The authors wish to thank Professor H Fukuda of the Department of Orthopaedic Surgery, Tokai University School of Medicine, for his critical review of this manuscript. The authors also thank E Miyakita, MD, T Abe, MD, and Y Harashima, MD of the Department of Urology, Tokai University School of Medicine for their valuable advice and technical support.

\section{References}

1 Frankel HL, Hancock DO, Hyslop G et al. The value of postural reduction in the initial management of closed injuries of the spine with paraplegia and tetraplegia. Paraplegia 1969; 7: 179-192.

2 Zancolli E. Functional restoration of the upper limbs in traumatic quadriplegia. Structural and dynamic basis of hand surgery. 2nd edn. JB Lippincott: Philadelphia 1979, pp 229-262.

3 Ditunno JF Jr, Young W, Donovan WH, Creasey G. The international standard booklet for neurological and functional classification of spinal cord injury. Paraplegia 1994; 32: 70-80.

4 Mizukami M, Kawai N, Iwasaki Y et al. Relationship between functional levels and movement in tetraplegic patients: A retrospective study. Paraplegia 1995; 33: 189-194.

5 Tamagaki T. Cervical spinal cord injury: Functional level and transfer ability (in Japanese). Sekituisekizui (Spine \& Spinal Cord) 1996; 9: 193-197.

6 Yabe Y. Spinal cord injuries (in Japanese). In: Imai G (ed). Rehabilitation. Ishiyaku: Tokyo 1972, pp 138-174. 
7 Yarkony GM et al. Rehabilitation outcomes in complete C5 quadriplegia. Am J Phys Med Rehabil 1988; 67: 73-76.

8 Yarkony GM, Roth EJ, Heinemann AW, Lovell L. Rehabilitation outcomes in C6 tetraplegia. Paraplegia 1988; 26: 177 - 185.

9 Shimada K, Tokioka T. Sequential MRI studies in patients with cervical cord injury but without bony injury. Paraplegia 1995; 33: $573-578$.
10 Barnes R. Paraplegia in cervical spinal injuries. $J B J S 1948$; 30B: $234-244$.

11 Kinoshita H. Pathology of hyperextension injuries of the cervical spine. Paraplegia 1994; 32: $367-374$ 